\title{
Carrot Seed Oil
}

National Cancer Institute

\section{Source}

National Cancer Institute. Carrot Seed Oil. NCI Thesaurus. Code C107280.

The oil extracted from the seeds of Daucus carota. Carrot seed oil is primarily used in skin treatment preparations. 